\title{
Impact and Assessment of Urban Wind Environment Change on Architectural Heritage Protection
}

\author{
Yi Xiaolie ${ }^{1, *}$, Zheng Lipeng ${ }^{2}$ \\ ${ }^{12}$ School of Architecture, South China University of Technology; State Key Laboratory of Subtropical Building Science ,Guangzhou \\ 510640, Guangdong,China
}

\begin{abstract}
In view of the contradiction between urban construction and protection of architectural heritage, this paper analyzes the hidden dangers of wind and fire protection of architectural heritage from the perspective of wind environment impact of high-rise buildings. The wind environment simulation and fire simulation based on computational fluid dynamics are used to study the typical building heritage cases in Guangzhou. The wind environment indicators that affect the comfort, safety and fire development of the wind environment of the building heritage are explained, so as to form a strategy for evaluating the impact of wind environment of high-rise buildings on the protection of building heritage.
\end{abstract}

\section{Introduction}

The change of urban wind environment has always been a hot research and concern at home and abroad. On the one hand, the rapid urban expansion and high-intensity construction cause the wind speed to slow down in the urban area, resulting in a large area of quiet wind area aggravating the phenomenon of air pollution and heat island effect. Many cities have put forward improvement measures such as wind corridor planning [1]. On the other hand, urban high-rise buildings have become the main factors affecting the wind environment. At present, urban renewal and construction are in full swing in China. The sharp increase of urban building height and planning adjustment will significantly change the regional wind environment conditions, producing adverse wind environment effects, disturbing the surrounding air flow conditions, damaging the comfort of the wind environment and the safety of pedestrians and buildings [2], making the regional architectural heritage protection face new challenges.

In view of the interference phenomenon of urban highrise buildings on the wind environment of surrounding buildings, scholars at home and abroad mainly focus on the comfort and safety of pedestrian wind environment around high-rise buildings [3], the wind load interference effect of group high-rise buildings, and the structural wind load interference effect of adjacent low-rise buildings. The research methods are also extended from the traditional field measurement to wind tunnel experiments and CFD simulation method. Xie Zhenyu summed up the adverse effects of high-rise buildings on the outdoor wind environment which including increasing wind speed and causing airflow chaos, and result in "narrow pipe effect" ,"Wind funnel effect", "shelter effect" and "street canyon effect"[4]. Zhang Min and Guan Jiping studied the wind load interference effect of group high-rise buildings, and compared the wind tunnel test results with the numerical simulation method. They explained the applicable conditions and conditions of the numerical simulation method, but the research focus is on the wind resistance design of high-rise buildings [5-6]. Gu Ming and shangluxi pay attention to the wind load interference effect of high-rise buildings on the adjacent low flat roof buildings. They systematically study the lifting coefficient and wind pressure coefficient of low-rise buildings under different wind direction angles, building height and spacing, but do not involve the situation of sloping roof [7-8]. It can be seen that there is little research on the impact of wind environment of high-rise buildings on the surrounding architectural heritage. Due to the particularity of building heritage, only some scholars study from the perspective of architectural heritage disaster prevention [9-10], and fail to systematically analyze and evaluate the impact of wind environment changes on pedestrian wind environment and building wind load under the interference of high-rise buildings.

In this paper, the typical building heritage cases in Guangzhou are selected, and the impact of wind environment effect of regional high-rise buildings on architectural heritage is enumerated. It is shown that the wind environment index affecting the protection and utilization of building heritage can be obtained by using the wind environment simulation and fire simulation method based on computational fluid dynamics (CFD), so as to form the assessment methods and Strategies of the effect of architectural heritage in the wind environment of urban high-rise buildings.

\footnotetext{
* Corresponding author: hillyyi@163.com 


\section{Change of urban wind environment and hidden danger of architectural heritage}

When the urban wind flow meets the obstruction of highrise buildings, it will produce strong vortex wind at the corner of the building and the windward front, and produce a long distance wind shadow area at the back of the building [11].The wind speed in the wind shadow area will be significantly reduced if the building heritage is located in the windward downstream of the high-rise building, but the negative wind pressure on the roof of the building heritage will be amplified. When the building heritage is located in the windward upstream of high-rise buildings, the wind speed will increase within a certain distance, and the roof of architectural heritage will even show obvious positive pressure. In addition, there is a complex interference phenomenon of wind environment between high-rise buildings, especially when the wind channel between high-rise buildings becomes narrow. It will produce a slit effect resulting in the rapid increase of wind speed and the decrease of wind pressure [12].
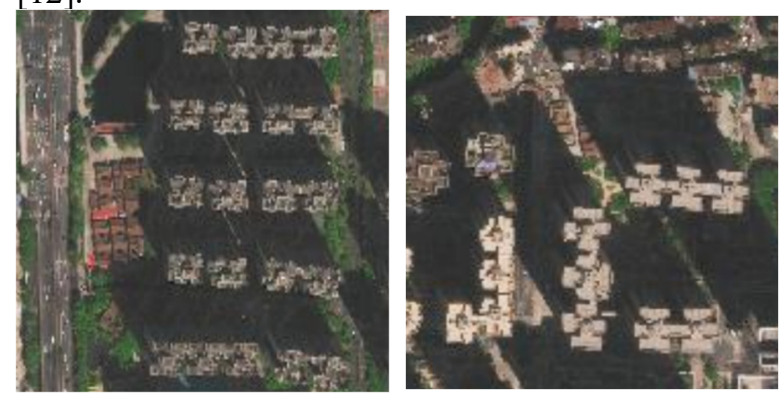

Fig1. Liede village in Guangzhou.

Fig2. Yangji village in Guangzhou.

According to the layout characteristics of high-rise buildings and architectural heritages in Guangzhou, the common hidden dangers of wind environment are as follows: first, the layout of buildings adjacent to high-rise buildings or super high-rise buildings. For example, after the overall reconstruction of Liede village in Guangzhou, the newly-built villagers' houses are close to the ancestral hall area (Fig.1); the second is that the architectural heritage is affected by the slit effect between high-rise buildings, such as the removal of the ancestral hall in Yangji village, Guangzhou. It's located between the gaps of high-rise residential buildings (Fig. 2).

Therefore, due to the layout of high-rise buildings in the city, adverse wind environment effects will appear, resulting in abnormal wind speed and wind pressure, which will affect the protection and utilization of regional architectural heritage. First of all, the building heritage is located in the wind shadow area of high-rise buildings. Low ambient wind speed and the increase of quiet wind days are not conducive to the loss of pollutants and reduce people's thermal environment comfort; secondly, the higher wind speed of the environment is not conducive to crowd activities, and strong wind may hurt people. At the same time, excessive wind speed will promote the spread of building fire, because wind speed is closely related to fire risk; Finally, the strong environmental wind leads to the increase of wind pressure and wind load on architectural heritage, which is easy to lead to the wind disaster damage. Especially in the coastal typhoon prone area of Guangzhou, we should pay more attention to the amplification effect of wind environment on the destructive force of high-rise buildings.

\section{Evaluation methods and standards}

\subsection{Simulation of outdoor wind environment of Architectural Heritage}

Computational fluid dynamics (CFD) simulation is a research method of building wind environment which is often used in the stage of urban planning and design. It can quickly and accurately calculate the urban wind environment. The mature CFD simulation software includes ANSYS fluent, PHOENICS and so on. The research on the calculation model shows that the prediction results of SST $\kappa-\varepsilon$ turbulence model based on Reynolds average method are close to the experimental results, and the simulation results of RNG $\kappa-\varepsilon$ model are also in good agreement with the measured data of wind environment.

Computational domain, boundary conditions and mesh generation are the main factors affecting the simulation results:

- The wind field calculation domain is divided into inflow, outflow and building area. The building area is based on the height $\mathrm{H}$ of high-rise building, centered on the assessed building heritage, and the radius of no less than $2 \mathrm{H}$ is the simulated building area. According to the building wind environment test and evaluation standard of Guangdong Province, the inflow distance is greater than $5 \mathrm{H}$, the outflow distance is greater than $10 \mathrm{H}$, the calculation domain height is greater than $4 \mathrm{H}$, and the maximum blocking ratio of wind direction incoming flow is not more than $5 \%$.

- The exponential rate model is used to simulate the gradient wind at the entrance boundary of the calculation domain. The roughness index $\alpha=0.22$ is taken as the geomorphic type. The outlet boundary is the pressure outlet, and the top and both sides are symmetrical walls.

- The minimum accuracy of the calculation grid in the key assessment area should be $1 / 10$ of the building scale, at least 3 or 4 layers of grid within the vertical $1.5 \mathrm{~m}$ height range. The grid should be densified in the area where the flow field is expected to change greatly, and the growth ratio of the grid size should not exceed 1.2.

\subsection{Architectural heritage fire simulation based on environmental wind speed}

Large eddy simulation (LES) is used to describe the movement of fire plume in architectural heritage fire dynamics simulation (FDS). The three-dimensional unsteady Navier Stokes equation driven by heat is solved by numerical method. The process of smoke flow and heat transfer in fire can be calculated accurately, and the physical quantities such as temperature, velocity and gas concentration in each part of the fire can be obtained. At 
the same time, FDS simulation process can consider the influence factors of environmental wind speed and wind direction.

- The simulation domain of FDS is mainly the interior space of the building, but additional calculation domain should be set at the top of the building outdoor to meet the fire spread through the roof. At the same time, the calculation domain at the external opening of the building is extended outward by more than $1 \mathrm{~m}$, so as not to affect the smoke flow and air inflow at the opening [13].

- Considering the influence of ambient wind speed on fire development, the boundary is set as periodic to simulate infinite flow field.

- The density of calculation grid directly affects the accuracy of simulation solution. The appropriate mesh size is related to the characteristic diameter of fire source [14]. When the minimum grid size is $1 / 4$ to $1 / 16$ of the characteristic diameter of fire source, the balance between simulation accuracy and calculation efficiency can be achieved. The characteristic diameter $\mathrm{d} *$ of the fire source is calculated from the heat release rate $\mathrm{Q}$ of the fire source (formula 1).

$$
D^{\circ}=\left(\frac{\dot{Q}}{\rho_{\infty x} \mathrm{c}_{p} T_{\infty} \sqrt{g}}\right)^{\frac{2}{5}}
$$

Where: $q$ is the heat release rate of the fire source; $\rho$ $\infty$ is the air density of $1.204 \mathrm{~kg} / \mathrm{m}^{3}, \mathrm{cp}$ is the air specific heat capacity of $1.005 \mathrm{~kJ} / \mathrm{kg} . \mathrm{k}, \mathrm{t} \infty$ is the ambient air temperature of $293 \mathrm{k}\left(20^{\circ} \mathrm{C}\right)$, and $\mathrm{g}$ is the gravity acceleration of $9.81 \mathrm{~m} / \mathrm{s}^{2}$.

\subsection{Evaluation standard of wind environment}

\subsubsection{Comfort and safety assessment of pedestrian wind environment}

The wind environment comfort assessment is based on the average wind speed $\mathrm{V}$ at pedestrian height. Firstly, the average wind speed ratio $\mathrm{R}=\mathrm{Vr} / \mathrm{V} 0$ is calculated (The ratio of the average wind speed $\mathrm{Vr}$ to the average wind speed V0 at the height of $10 \mathrm{~m}$ corresponding to the local standard landform), while the average wind speed at pedestrian height is $\mathrm{V}=\mathrm{RV}_{10}\left(\mathrm{~V}_{10}\right.$ is the average wind speed at $10 \mathrm{~m}$ height of local standard landform).

The average wind speed ratio $r$ under the dominant wind direction in summer should not be less than 0.2 , otherwise the wind environment would feel hot. In winter, the average wind speed ratio $\mathrm{R}$ should not be greater than 2.0, otherwise the wind environment would feel cold. When the maximum average wind speed is greater than $5 \mathrm{~m} / \mathrm{s}$, the pedestrian wind environment is not comfortable.

Gust wind speed is adopted for wind environment safety assessment. Gust wind speed at pedestrian height $\mathrm{V}$ $'=\beta_{\mathrm{gh}} \mathrm{V}, \beta_{\mathrm{gh}}$ is the fluctuation coefficient of wind speed. In urban areas with dense buildings, when the basic wind pressure is greater than or equal to $0.5 \mathrm{KN} / \mathrm{m}^{2}$, the wind speed fluctuation coefficient at $1.5 \mathrm{~m}$ height is 1.69 ; when the basic wind pressure is less than $0.5 \mathrm{KN} / \mathrm{m}^{2}$, the wind speed fluctuation coefficient at $1.5 \mathrm{~m}$ height is 1.58 . The safety degree of pedestrian wind environment is judged according to the annual frequency of gust wind speed $\mathrm{V}$ 'greater than $15 \mathrm{~m} / \mathrm{S}$ (Table 1).

Table 1. Safety assessment of pedestrian wind environment

\begin{tabular}{|c|c|c|}
\hline \multirow{2}{*}{$\mathrm{P}\left(\mathrm{V}^{\prime}>\right.$} & Safe & $<0.05 \%(<2$ times/year $)$ \\
\cline { 2 - 3 } & & $0.05-0.3 \%$ \\
$15 \mathrm{~m} / \mathrm{s})$ & Risky & $\begin{array}{c}(\geq 2 \text { times/year }, \leq 12 \text { times } / \text { ye } \\
\text { ar })\end{array}$ \\
\cline { 2 - 3 } & Danger & $>0.3 \%(>12$ times $/$ year $)$ \\
\hline
\end{tabular}

\subsubsection{Wind protection valuation of architectural heritage wind environment}

The influence of regional wind environment change on the wind resistance performance of architectural heritage mainly depends on the effect of wind pressure and wind load. The height and slope of roof, whether there are gables and vertical ridges will lead to different wind load distribution of building roof.The results show that the height of the ridge can increase the average wind pressure and fluctuating wind pressure of the windward roof, and reduce the overall upward lifting force of the roof. The gable out of the roof is beneficial to reduce the average negative pressure and fluctuating wind pressure at the vertical ridge and the roof corner area, and greatly reduce the most unfavorable wind pressure of the roof.

The wind environment simulation can calculate the average wind pressure coefficient distribution of building surface. If the wind pressure distribution varies greatly, and abnormal positive pressure occurs, it is necessary to check whether the wind load intensity exceeds the maximum limit value of regional wind load. When there is obvious negative pressure area, it is necessary to judge whether the position is located at the roof corner, roof structure and other weak parts.

\subsubsection{Fire protection valuation of architectural heritage wind environment}

The spread of building heritage fire is mainly affected by fire load, heat release rate and fire space condition. Different fire environment leads to different fire development. By comparing the influence of fire plume on buildings in downwind direction under different wind speeds, whether the high temperature smoke flow reaches the critical radiation intensity of ignition is analyzed. When the radiant heat is low, the temperature of the outer surface of the building cannot reach the ignition point, so it is impossible to ignite. 


\section{Case analysis and evaluation}

\subsection{Influence of wind environment of high-rise buildings on architectural heritage}

Taking the planning and construction of Guangzhou baietan international financial center as an example, there are architectural heritages of Guangzhou Tongsheng machinery factory in the plot, and several super high-rise building towers will be built nearby. According to the meteorological data of Guangzhou, the typhoon weather, rainy and humidity season and the dominant wind direction in summer and winter are selected for analysis. CFD simulation analysis can obtain the wind speed ratio, average wind speed and gust wind speed of each measuring point in the wind environment of building model, as well as the cloud chart of wind speed ratio, wind speed vector diagram and streamline diagram under different wind directions. In addition, the calculation results of wind pressure, wind speed and wind pressure coefficient on the external surface of buildings can be displayed intuitively (Fig.3), which is helpful to judge the change of wind environment and the disturbance degree of architectural heritage. The results show that:

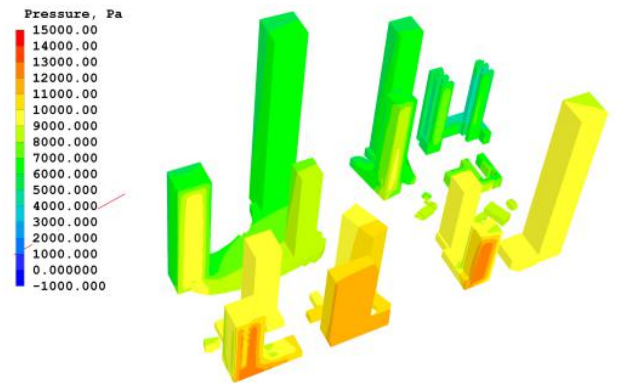

Fig3. Wind pressure distribution on facade of building complex

- Typhoon weather belongs to extreme strong wind weather, and the amplification effect of wind environment will enhance the damage of typhoon. Through the wind environment simulation to verify the safety of structure wind load, the positive and negative pressure parts of wind load are obtained. For sloping roof buildings, the negative pressure is the main reason for the roof overturned by strong wind.

- Under the weather of rainy and humidity, if the architectural heritage is located in the wind shadow area of high-rise buildings, the ventilation performance of the area will become worse, the wind speed will slow down and the air humidity will be more obvious, which is not conducive to the maintenance of the architectural heritage.

- Under the dominant wind direction in summer and winter, affected by the surrounding building layout and high-rise buildings, the outdoor wind speed reaches good thermal comfort in summer, but there is a strong wind downward along the high-rise buildings in winter.

\subsection{Influence of environmental wind speed on fire spread of architectural heritage}

In order to evaluate the impact of environmental wind speed on the fire protection performance of architectural heritage, taking Chen's Academy, a typical ancestral temple building in Guangzhou, as an example, the main hall and east hall with the largest fire load were selected for fire simulation. The main hall and the east hall is made of dense wooden frame, and the roof height accounts for about $1 / 3$ of the elevation. The fire scenario is that the wooden frame is ignited after an electrical fire in the main hall, and the roof will burn through after the fire flashover. The roof fire is affected by the wind speed of the environment, which will affect the East Hall building in the downwind direction. When the ambient wind speed is $2,3,4,6,8 \mathrm{~m} / \mathrm{s}$, the influence of roof flame on the roof temperature of east hall is calculated to judge whether the gable ridge and building spacing can prevent the fire spreading.

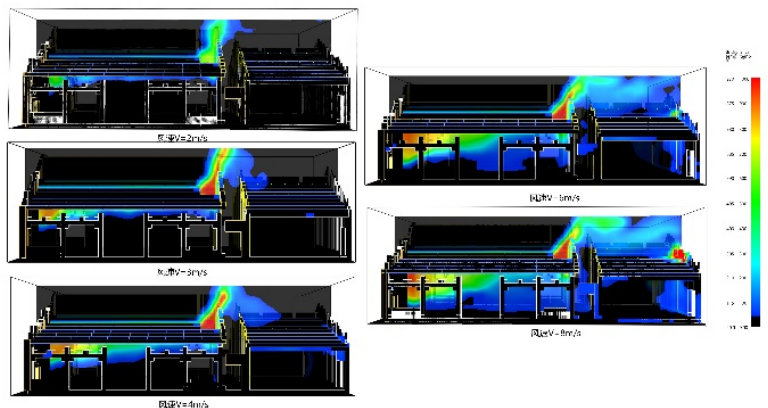

Fig4. Wind speed and roof fire spread

The results show ( Fig.4) that when the wind speed is $2 \mathrm{~m} / \mathrm{s}$, the fire smoke rises vertically, the gable blocks the flow of high temperature smoke, and the roof temperature changes little. When the wind speed is $3 \mathrm{~m} / \mathrm{s}$, the roof flame exceeds the gable, and the smoke enters the lane space, causing the roadway space and east hall gable to heat up. When the wind speed is $4 \mathrm{~m} / \mathrm{s}$, the height of fire flame increases, and the fire plume flows downward under the influence of wind. The tunnel temperature reaches $140^{\circ} \mathrm{C}$ and the roof temperature of the east hall reaches $120^{\circ} \mathrm{C}$. When the wind speed is $6 \mathrm{~m} / \mathrm{s}$, the influence distance of the fire plume increases, and the high-temperature smoke is blocked by the vertical ridge of the east hall roof, forming a high-temperature part of $400{ }^{\circ} \mathrm{C}$. When the wind speed is $8 \mathrm{~m} / \mathrm{s}$, the fire plume will accumulate seriously on the roof of the east hall, and the roof temperature can reach $800{ }^{\circ} \mathrm{C}$, which will cause roof damage and lead to longdistance ignition.

It can be seen that after the flashover of the main hall fire in the ancestral hall building group, the roof burning through flying fire is obviously affected by the environmental wind speed. When the wind speed is greater than $4 \mathrm{~m} / \mathrm{s}$, attention should be paid to the fire safety of the building group. At this time, the fire of single building is easy to spread by the wind.

\section{Conclusion}

From the perspective of architectural heritage protection, this paper analyzes the hidden dangers of wind environment changes caused by urban high-rise buildings, and evaluates two architectural heritages in Guangzhou by using wind environment simulation and fire simulation, which illustrate the application of specific evaluation 
methods and evaluation standards.

-The layout of urban high-rise buildings is the cause of adverse wind environment effect, which not only affects the comfort and safety of pedestrian wind environment, but also causes interference effect on the wind load of adjacent architectural heritage. Severe typhoon weather will enlarge the damage caused by wind disaster.

-The wind environment simulation and fire simulation based on computational fluid dynamics (CFD) can effectively reflect the interference effect of high-rise buildings on regional wind environment and the impact of environmental wind speed on the spread of fire, which is conducive to evaluate the impact of wind environment on the protection and utilization of architectural heritage in the early stage of urban renewal planning and design.

- The simulation analysis can obtain the wind environment indicators that affect the comfort of pedestrian wind environment, the safety of building structure and the development of fire. The wind environment comfort evaluation index adopts the average wind speed of pedestrian height, and the wind environment safety evaluation index adopts the gust wind speed of pedestrian height. The safety assessment of architectural heritage structure is based on the wind pressure distribution on the external surface of the building and the standard wind load. The influence of wind speed on the spread of architectural heritage fire can be judged by temperature distribution and thermal radiation.

\section{References}

1. A Ren Chao, Yuan Chao, he Zhengjun, et al. Study on Urban Ventilation corridor and its planning application [J]. Urban Planning Journal, 2014 (03): 52-60.

2. Zhuang Zhi, Yu Yuanbo, ye Hai, et al. Research status of CFD simulation technology for building outdoor wind environment $[\mathrm{J}]$. Architectural science, 2014,30 (02): 108-114.

3. $\mathrm{Xu}$ Xiaoda. Distribution characteristics of average wind speed at pedestrian height around super highrise buildings and wind environment assessment [D]. 2019.

4. Xie Zhenyu, Yang ne. Shape optimization design strategy for improving outdoor wind environment of high-rise buildings [J]. Acta architecture, 2013, 000 (002): 76-81.

5. Zhang Min, Lou Wenjuan, he gejun, et al. Numerical study on wind load disturbance effect of high-rise buildings [J]. Engineering mechanics, 2008 (01): 179185.

6. Guan Jiping, Chen Wei, Zhu Ledong. Study on group interference effect of wind environment in high-rise buildings [C] National Conference on structural wind engineering. 2009

7. Shang Luxi. Wind load interference effect of high-rise buildings on low rise flat roof buildings [D]. 2017

8. Gu Ming, Huang Peng. Research status and Prospect of wind load disturbance on high-rise buildings [J]. Journal of Tongji University (NATURAL SCIENCE EDITION), 2003, 31 (7): 762-766

9. Liang Haoyan, Meng Qinglin, Li Xiaohui, et al. Study on wind environment assessment method of Lingnan old city renewal and Reconstruction Planning -- a case study of Yuzhu old city renewal planning in Huangpu District of Guangzhou City [J]. Southern architecture, 2018 (04): 34-39

10. Liu Pengfei, Zou Fang, Ouyang Huiting, et al. Research on the local renewal mode of old urban area based on wind environment simulation: a case study of Taiping old street in Changsha City [J]. Southern architecture, 2020 (01): 47-52

11. Yang Li, Liu Xiaodong, sun Biman. Research progress of building wind environment $[\mathrm{J}]$. Building science, 2018, 034 (012): 147-156

12. Fu Xiaojian, Yan Xiaoping, Xu Minghui. Numerical study on slit effect of wind load on twin tower buildings [J]. Shanxi architecture, 2007 (15): 82-84

13. Zhu Shi, Huo Ran, Hu Longhua, et al. Influence of grid generation and calculation area extension at opening on FDS simulation results $[\mathrm{J}]$. Journal of safety and environment, 2008 (04): 133-137

14. Deng Ling. Grid analysis in FDS field simulation [J]. Fire science and technology, 2006, 25 (2): 207-210 